\title{
On-Off Type Mechanofluorochromism of a Novel Fluorescent Amorphous Molecular Material, $\boldsymbol{N}$-\{4-[Bis(4-methylphenyl)amino]benzylidene $\}$ aniline
}

\author{
Satoshi Manabe, Eisuke Nagata and Hideyuki Nakano*
}

Department of Applied Chemistry, Muroran Institute of Technology, 27-1, Mizumoto-cho, Muroran, Hokkaido 050-8585, Japan

\begin{abstract}
The title compound (BMBZA) was designed and synthesized as a novel fluorescent amorphous molecular material. BMBZA was found to exhibit solvatofluorochromism and to readily form an amorphous glass by cooling the melt on standing. In addition, the morphological change from crystalline state to amorphous one could be induced by mechanical grinding. Although fluorescence was scarcely observed for the crystalline sample of BMBZA, the grinding the sample was found to enhance the fluorescence emission, that is, BMBZA exhibited on-off type mechanofluorochromism.
\end{abstract}

Solid state organic fluorescent materials have been investigated extensively from both viewpoints of fundamental sciences and practical applications for use in, e.g., emitting materials of organic electroluminescent devices and emitting field-effect transistors. ${ }^{1-6}$ Fluorescence switching and/or modification of such materials are also the subjects of interest. Recently, the phenomena of reversible fluorescence color changes of organic and organometallic crystals induced by mechanical stress such as grinding, have been attracted attentions. The phenomena are referred to as "mechanofluorochromism","mechanochromic luminescence", "piezochromic luminescence", and so on. A variety of mechanofluorochromic materials have been created and investigated..$^{7-19}$ In most cases, it is believed that changes in intermolecular interaction due to disordering the molecules in the crystals resulted in their mechanofluorochromism. It is of interest and of importance to create novel mechanofluorochromic materials and to elucidate the mechanism of the phenomena.

In contrast to most reported mechanofluorochromic materials exhibiting fluorescence in both pristine and ground samples, on-off type mechanofluorochromic materials have been reported very recently. ${ }^{20-24}$ Such on-off type mechanofluorochromic materials are expected to provide images with excellent contrast; however, only few examples exhibiting on-off type mechanofluorochromism have been known at present.

We have been performing studies of the creation of photo- and electro-active amorphous molecular materials,

*To whom correspondence should be addressed.

E-mail: nakano@mmm.muroran-it.ac.jp namely low molecular-mass materials that readily form amorphous glasses above room temperature. ${ }^{25-29}$ Recently, we have found that 4-di(4-methylphenyl)amino]benzaldehyde (BMABA) and 4-[bis(9,9-dimethylfluoren-2yl)amino]benzaldehyde (BFABA) exhibited fluorescence in both crystalline state and amorphous one, and that their fluorescence spectra in amorphous states were different from those in crystalline states. ${ }^{30,31}$ It was suggested that relatively large conformational changes in their excited states took place to have twisted intramolecular charge transfer (TICT) structures in amorphous state as well as in solution, whereas such conformational changes of molecules seemed to be restricted in crystalline state due to narrow space in the crystal, resulting in difference emission color depending on their morphologies. We have finally found that BMABA and BFABA exhibit mechanofluorochromism due to morphological change from crystalline state to amorphous one by mechanical grinding. Thus, these results may provide a concept of molecular design for a new series of mechanofluorochromic materials. That is, emitting materials with both abilities of large conformational change taking place in excited state and of glass formation by grinding the crystal become candidates for new mechanofluorochromic materials.

According to such concept of molecular design, we have designed and synthesized a novel amorphous molecular material,

$N$-\{4-[bis(4-methylphenyl)amino]benzylidene\}aniline (BMBZA), and investigated the fluorescence properties in solid states as well as in solution. And finally, BMBZA was found to exhibit on-off type mechanofluorochromism

BMBZA was synthesized by condensation reaction of BMABA with aniline in toluene (Chart 1) and purified by recrystallization from ethanol. BMBZA was identified by NMR spectroscopy, mass spectrometry, and elemental analysis. $^{32}$

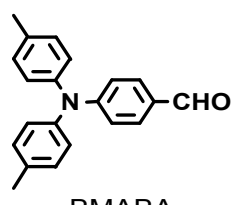

BMABA

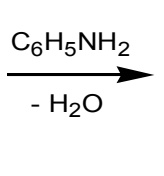

Chart 1. Synthesis of BMBZA

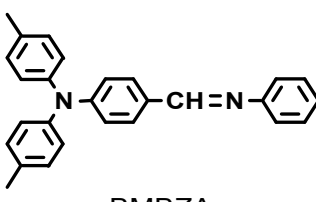

BMBZA 
BMBZA was found to exhibit solvatofluorochromism, the fluorescence color depending on the kind of solvents. As indicated in Table 1 and Figure 1, fluorescence spectra were found to be shifted to longer wavelength with the increase in solvent polarity $\left(\mathrm{E}_{\mathrm{T}}(30)\right.$ values $^{33}$ were indicated as the parameter of solvent polarity in Table 1), whereas the electronic absorption spectra were almost independent from the solvent. BMABA and BFABA exhibited the similar absorption and emission properties, and hence BMBZA was suggested to undergo relatively large conformational change to take TICT structure in the excited state in solutions.

Table 1. Electronic absorption and fluorescent properties of BMBZA in various solvents. ${ }^{\mathrm{a}}$

$\begin{array}{ccccc}\text { solvent } & \begin{array}{c}\mathrm{E}_{\mathrm{T}}(30) \\ / \mathrm{kcal} \mathrm{mol}^{-1}\end{array} & \begin{array}{c}\lambda_{\mathrm{abs}} \\ / \mathrm{nm}\end{array} & \begin{array}{c}\varepsilon \\ / \mathrm{M}^{-1} \mathrm{~cm}^{-1}\end{array} & \begin{array}{c}\lambda_{\mathrm{FL}} \\ / \mathrm{nm}\end{array} \\ \text { toluene } & 33.9 & 379 & 3.0 \times 10^{4} & 467 \\ \text { THF } & 37.4 & 375 & 3.2 \times 10^{4} & 491 \\ \text { acetone } & 42.2 & 373 & 3.1 \times 10^{4} & 519 \\ \text { acetonitrile } & 45.6 & 372 & 3.3 \times 10^{4} & 540\end{array}$

${ }^{\mathrm{a}} \mathrm{E}_{\mathrm{T}}(30)$ : parameter of solvent polarity. ${ }^{33} \quad \lambda_{\mathrm{abs}}$ : wavelength at electronic absorption maximum. $\varepsilon$ : molar extinction coefficient at $\lambda_{\mathrm{abs}}$. $\lambda_{\mathrm{FL}}$ : wavelength at fluorescent maximum.

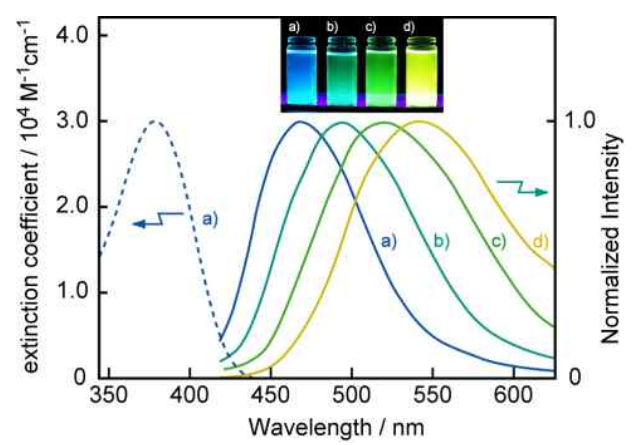

Figure 1. Electronic absorption and fluorescence spectra of BMBZA in various solvents. Inset: Photographs of fluorescent solutions upon UV irradiation from their bottoms. a) toluene, b) THF, c) acetone, d) acetonitrile.

BMBZA was confirmed to readily form an amorphous glass by cooling the melt sample on standing. In addition, morphological change into amorphous state by grinding the crystalline sample was suggested by X-ray diffraction (XRD) and differential scanning calorimetry (DSC). While the crystalline sample obtained by recrystallization from ethanol showed sharp diffraction peaks for the XRD pattern (Figure 2a), only broad halo was observed for the sample obtained by cooling the melt (Figure 2b), indicating that the sample obtained by cooling the melt was an amorphous glass. When the crystalline sample was ground, XRD patterns became broader and weaker (Figure 2c), suggesting that the morphology was changed partly from crystalline state to amorphous one. When the ground sample was annealed at $100{ }^{\circ} \mathrm{C}$ for $30 \mathrm{~min}$, the XRD patterns were returned to be sharp and intense (Figure 2d) due to recrystallization.

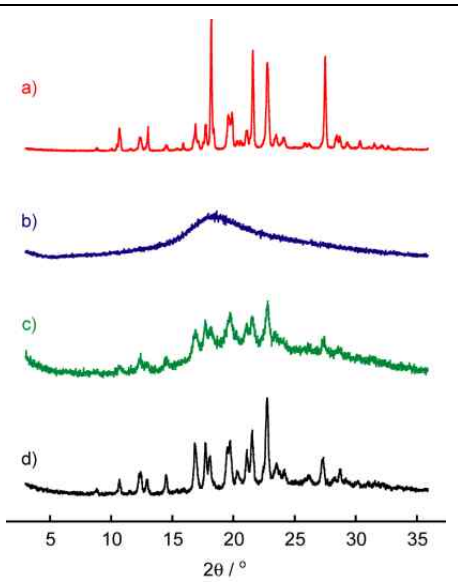

Figure 2. XRD patterns of BMBZA. a) crystalline sample. b) glassy sample obtained by cooling the melt. c) sample obtained by grinding the crystals. d) sample obtained by annealing the ground sample.

Regarding the DSC of BMBZA, whereas the crystalline sample exhibited only one endothermic peak at $136{ }^{\circ} \mathrm{C}$ attributable to melting (Figure 3a), the sample obtained by cooling the melt showed well-defined glass transition phenomenon at $25^{\circ} \mathrm{C}$ followed by crystallization at $82{ }^{\circ} \mathrm{C}$ and melting at $136{ }^{\circ} \mathrm{C}$ (Figure $3 \mathrm{~b}$ ). When the sample obtained by grinding the crystal was heated (Figure $3 \mathrm{c}$ ), clear glass transition phenomenon could not be observed; however, an exothermic peak was observed at $36{ }^{\circ} \mathrm{C}$. The result suggested that the crystalline sample was partly changed to amorphous state by grinding and recrystallization took place on heating. Thus, BMBZA was suggested to have both abilities of large conformational change taking place in excited state and of glass formation by grinding the crystal.

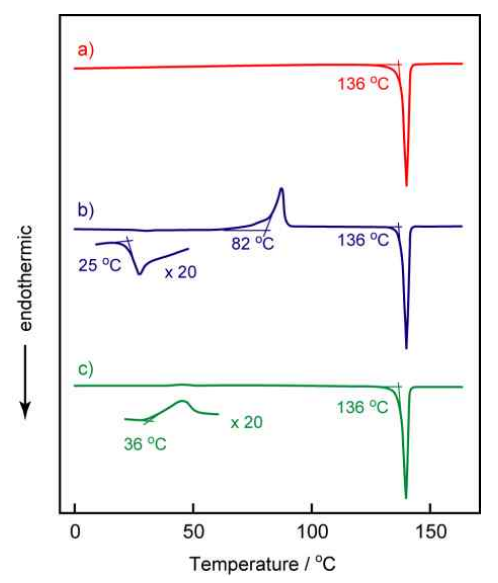

Figure 3. DSC curves of BMBZA. a) crystalline sample. b) glassy sample. c) sample obtained by grinding the crystal.

Then we investigated the emitting property of BMBZA in solid states. Although the fluorescence was scarcely observed for crystalline sample, an amorphous glassy sample obtained by cooling the melt was found to emit dark green fluorescence upon irradiation with UV light $(365 \mathrm{~nm})$. In 
addition, we have found that BMBZA exhibited on-off type mechanofluorochromism. Whereas fluorescence was scarcely observed for crystalline sample, the grinding the sample enhanced the fluorescence emission as shown in Figure 4. When the resulting ground sample was sufficiently annealed at ca. $100{ }^{\circ} \mathrm{C}$, such emission was disappeared.
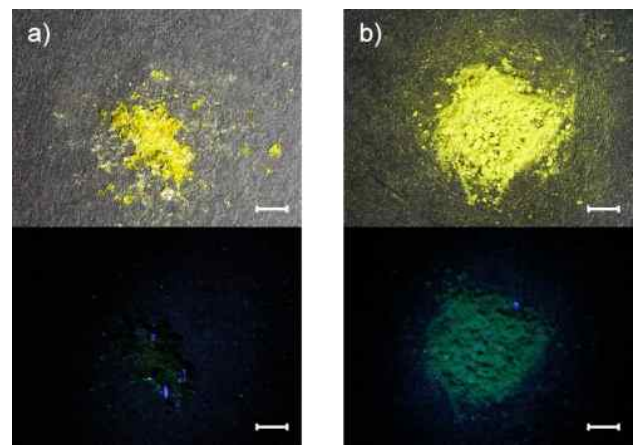

Figure 4. Photographs of the samples under room light (top) and under UV light (bottom). a) crystalline sample. b) ground sample. scale bar: $2 \mathrm{~mm}$.

In order to gain further information, fluorescence spectrum of the sample obtained by grinding the crystal was compared with that of the amorphous glassy sample obtained by cooling the melt. As shown in Figure 5, these spectra were similar to each other, the fluorescence maximum of the ground sample $(480 \mathrm{~nm})$ being identical to that of the glassy sample. The result suggested that the emission observed for the ground sample came from the amorphous area produced by grinding the crystal. Unlike BMABA and BFABA, fluorescence of BMBZA was considerably quenched in the crystalline state as described above. Thus, the present onoff type mechanofluorochromism was due to morphological change from non-emissive crystalline state to emissive amorphous state induced by grinding. It is conceivable that conformational relaxation in the excited state is necessary to emit for BMBZA and enlargement of free volume by grinding the crystal allows such conformational change at the resulting amorphous area. It is noted that the present study verified the concept of molecular design for creating a new series of mechanofluorochromic materials as described above.

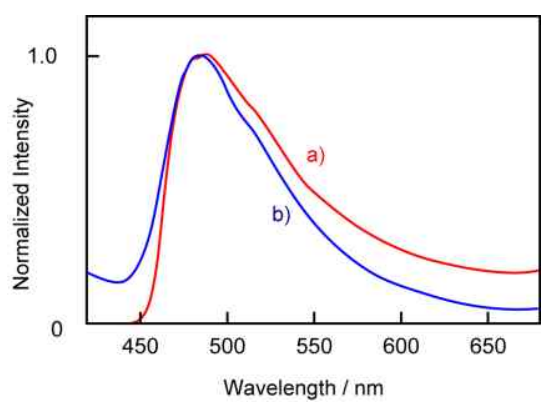

Figure 5. Fluorescence spectra of BMBZA in solid states. a) glassy sample obtained by cooling the melt. b) sample obtained by grinding the crystalline. $\lambda_{\mathrm{ex}}: 370 \mathrm{~nm}$
In summary, we have designed and synthesized a novel fluorescent amorphous molecular material, BMBZA, with both abilities of large conformational change taking place in excited state and of glass formation by grinding the crystal. And finally, BMBZA was found to be a new on-off type mechanofluorochromic material. The phenomenon was suggested to be due to morphological change from nonemissive crystalline state to emissive amorphous state induced by grinding.

KEYWORDS: mechanofluorochromism, fluorescence, amorphous molecular material, morphology.

Received June 2, 2014; Accepted June 10, 2014

\section{REFERENCES AND NOTES}

1. Shirota, Y. J. Mater. Chem., 2000, 10, 1-25.

2. Mitschke, U.; Baeuerle, P. J. Mater. Chem., 2000, 10, 1471-1507.

3. Guo, Y.; Yu, G.; Liu, Y. Adv. Mater., 2010, 22, 4427-4447.

4. Kim, J. H.; Watanabe, A.; Chung, J. W.; Jung, Y.; An, B.K.; Tada, H.; Park, S. Y. J. Mater. Chem., 2010, 20, 1062-1064.

5. Xiao, L.; Chen, Z.; Qu, B. Luo, J.; Kong, S.; Gong, Q.; Kido, J. Adv. Mater., 2011, 23, 926-952.

6. Bisri, S. Z.; Takenobu, T.; Sawabe, K.; Tsuda, S.; Yomogida, Y.; Yamao, T.; Hotta, S.; Adachi, C.; Iwasa, Y. Adv. Mater., 2011, 23, 2753-2758.

7. Chi, Z.; Zhang, X.; Xu, B.; Zhou, X.; Ma, C.; Zhang, Y.; Liu, S.; Xu, J. Chem. Soc. Rev., 2012, 41, 3878-3896.

8. Zhang, X.; Chi, Z.; Zhang, Y.; Liu, S.; Xu, J. J. Mater. Chem. C, 2013, 1, 3376-3390.

9. Lee, Y.-A. J. Am. Chem. Soc., 2003, 125, 7778-7779.

10. Sagara, Y.; Mutai, T.; Yoshikawa, I.; Araki, K. J. Am. Chem. Soc., 2007, 129, 1520-1521.

11. Sagara, Y.; Kato, T. Angew. Chem. Int. Ed., 2008, 47, $5175-5178$

12. Ito, H.; Saito, T.; Oshima, N.; Kitamura, N.; Ishizaka, S.; Hinatsu, Y.; Wakeshima, M.; Kato, M.; Tsuge, K.; Sawamura, M. J. Am. Chem. Soc., 2008, 130, 1004410045.

13. Yoon, S. J.; Chung, J. W.; Gierschner, J.; Kim, K. S.; Choi, M.-G.; Kim, D.; Park, S. Y. J. Am. Chem. Soc., 2010, 132, 13675-13683.

14. Luo, X.; Li, J.; Li, C.; Heng, L.; Dong, Y. Q.; Liu, Z.; Bo, Z. Tang, B. Z. Adv. Mater., 2011, 23, 3261-3265.

15. Dong, Y.; Xu, B.; Zhang, J.; Tan, X.; Wang, L.; Chen, J.; Lv, H.; Wen, S.; Li, B.; Ye, L.; Zou, B.; Tian, W. Angew. Chem. Int. Ed., 2012, 51, 10782-10785.

16. Shan, G.-G.; Li, H.-B.; Qin, J.-S.; Zhu, D.-X.; Liao, Y.; Su, Z.-M. Dalton Trans., 2012, 41, 9590-9593.

17. Xu, B.; Xie, M.; He, J.; Xu, B.; Chi, Z.; Tian, W.; Jiang, L.; Zhao, F.; Liu, S.; Zhang, Y.; Xu, Z.; Xu, J. Chem. Commun., 2013, 49, 273-275.

18. Shen, X. Y.; Wang, Y. J.; Zhao, E.; Yuan, W. Z.; Liu, Y.; Lu, P.; Qin, A.; Ma, Y.; Sun, J. Z.; Tang, B. Z. J. Phys. Chem. C, 2013, 117, 7334-7347.

19. Yuan, W. Z.; Tan, Y.; Gong, Y.; Lu, P.; Lam, J. W.; Shen, X. Y.; Feng, C.; Sung, H. H-Y.; Lu, Y.; Williams, I. D.; Sun, J. Z.; Zhang, Y.; Tang, B. Z. Adv. Mater., 2013, 25, 2837-2843. 
20. Luo, J.; Li, L.-Y.; Song, Y.; Pei, J. Chem. Eur. J., 2011, 17, 10515-10519.

21. Zhang, Y.; Sun, J.; Lv, X.; Ouyang, M.; Cao, F.; Pan, G.; Pan, L.; Fan, G.; Yu, W.; He, C.; Zheng, S.; Zhang, F.; ang, W.; Zhang, C. CrystEngComm, 2013, 15, 8998-9002.

22. Zhang, B.; Hsu, C.-H.; Yu, Z.-Q.; Yang, S.; Chen, E.-Q. Chem. Commun., 2013, 49, 8872-8874.

23.Zhang., Y.; Sun, J.; Zhuang, G.; Ouyang, M.; Yu, Z.; Cao, F.; Pan, G.; Tang, P.; Zhang, C.; Ma, Y. J. Mater. Chem. $C, \mathbf{2 0 1 4}, 2,195-200$.

24. Kwon, M. S.; Gierschner, J.; Seo, J.; Park, S. Y. J. Mater. Chem. C, 2014, 2, 2252-2557.

25. Ishikawa, W.; Inada, H.; Nakano, H.; Shirota, Y. Chem. Lett., 1991, 1731-1734.

26. Inada, H.; Ohnishi, K.; Nomura, S.; Higuchi, A.; Nakano, H.; Shirota, Y. J. Mater. Chem., 1994, 4, 171-177.

27. Ueta, E.; Nakano, H.; Shirota, Y. Chem. Lett., 1994, 2397-2400;

28. Utsumi, H.; Nagahama, D.; Nakano, H.; Shirota, Y. J. Mater. Chem., 2002, 12, 2612-2619.
29. Tanino, T.; Yoshikawa, S.; Ujike, T.; Nagahama, D.; Moriwaki, K.; Takahashi, T.; Kotani, Y.; Nakano, H.; Shirota, Y. J. Mater. Chem., 2007, 17, 4953-4963.

30. Mizuguchi, K.; Kageyama, H.; Nakano, H. Mater. Lett., 2011, 65, 2658-2661.

31. Mizuguchi, K.; Nakano, H. Dyes Pigm., 2013, 96, 76-80.

32. BMBZA: Yield: $63 \%$; m.p.: $136{ }^{\circ} \mathrm{C} ;{ }^{1} \mathrm{H}$ NMR $(500 \mathrm{MHz}$, $\left.\mathrm{CDCl}_{3}\right): \delta(\mathrm{ppm})=8.33(\mathrm{~s}, 1 \mathrm{H}), 7.69(\mathrm{~d}, 2 \mathrm{H}, J=8.9 \mathrm{~Hz})$, 7.37 (dd, 2H, $J=7.2,8.9 \mathrm{~Hz}), 7.18(\mathrm{t}, 1 \mathrm{H}, J=8.9 \mathrm{~Hz})$, $7.17(\mathrm{~d}, 2 \mathrm{H}, J=7.2 \mathrm{~Hz}), 7.11(\mathrm{~d}, 4 \mathrm{H}, J=8.3 \mathrm{~Hz}), 7.04(\mathrm{~d}$, $4 \mathrm{H}, J=8.3 \mathrm{~Hz}), 7.01(\mathrm{~d}, 2 \mathrm{H}, J=8.9 \mathrm{~Hz}), 2.33(\mathrm{~s}, 6 \mathrm{H})$; 13C NMR (125 MHz, $\left.\mathrm{CDCl}_{3}\right): \delta(\mathrm{ppm})=159.78,152.58$, $151.12,144.34,133.84,130.11,129.85,129.06,128.54$, 125.63, 125.35, 120.88, 120.25, 20.90; $\mathrm{MS}\left(\mathrm{M}^{+}\right)$: Found: 376.1936, Calcd for $\mathrm{C}_{27} \mathrm{H}_{24} \mathrm{~N}_{2}$ : 376.1939; EA: Found: C, 85.94; H, 6.47; N,7.41\%. Calcd for $\mathrm{C}_{27} \mathrm{H}_{24} \mathrm{~N}_{2}$ : C, 86.13; $\mathrm{H}, 6.43 ; \mathrm{N}, 7.44 \%$.

33. Solvents and Solvent Effects in Organic Chemistry, ed. by Reichardt, C., Weinheim, Wiley-VCH, 2003. 